tissues of the baby's hip joints, rendering them more vulnerable to pressure. The influence of genetic and environmental causes varies from one case to another. The late J. Edelstein, ${ }^{5}$ of Johannesburg, investigated the story that Bantu women never had babies with hip dislocations because they arried their babies on their backs with the infant's legs spread apart. Edelstein studied many infants at birth and found simply that Bantu women rarely gave birth to babies with this lesion. Again the genetic factor is stressed.

The Ministry of Health has recently produced a useful ittle memorandum. ${ }^{6}$ From the results of recent surveys it reports an incidence of congenital dislocation of the hip in 1.5 to 1.7 per thousand babies and the sex ratio of 1 male to 2.2 females. Ortolani's method of examining babies is illustrated to show doctors, midwives, and health visitors how :o carry it out. Early diagnosis will then enable orthopaedic surgeons to start treatment at the time which really matters. Otherwise (and this is still too common) infants will be brought to hospital when they start to walk or later. Adaptive dysplasia will then have developed in the acetabula or the femoral heads, when treatment must be much prolonged and the prognosis is unsatisfactory. ${ }^{7}$ The Ministry's document contains the questionable statement that " $85 \%$ of hip dislocations recover spontaneously." Without further discussion of the evidence, acceptance of this figure might lead to complacency which under no circumstances can this disorder permit.

\section{Puerperal Psychoses}

Despite conflicting views on the subject no good evidence has been found for regarding puerperal psychosis as distinct trom psychosis outside the puerperium. Many observers have failed to specify adequately the period of parturition studied, and many do not distinguish psychosis from neurosis or personality disorder. ${ }^{1}$ However, the risk of suicide ${ }^{2}$ and of hospital admission for psychosis $^{3}$ is diminished during pregnancy, while the risk of psychosis is increased during the puerperium."

If puerperal psychosis is defined as occurring within three months of delivery its incidence is probably about 1.4 cases per thousand pregnancies. ${ }^{5}$ Psychosis after abortion is even less frequent ${ }^{6}$ despite the fact that those who seek termination of a pregnancy include more mentally upset women than 3verage. $^{6}$ An unwanted pregnancy is itself often symptomatic of a neurosis or character disorder, ${ }^{8}$ and childbirth or abortion constitutes a threat to an already precarious equilibrium. M. Ekblad ${ }^{7}$ studied an extensive series of abortions carried out on psychiatric grounds. Though he reported that much residual disability followed abortions, he concluded that no more deleterious effect on the psyche was found than would have developed had the unwanted pregnancy been Allowed to continue. B. Jansson ${ }^{6}$ supported this view, and K. Höök, ${ }^{8}$ in following up nearly 300 cases in which abortion was refused, found an even higher level of disability. Pregnancy and childbirth appear to have little effect on a pre-existing psychosis, and the risk of deterioration cannot alone be regarded as an indication for terminating a pregnancy. ${ }^{9}$

The complex relationships which exist between reproductive and psychological factors are illustrated by the observation that neurotic women experience more pregnancies, miscarriages, stillbirths, and neonatal deaths, as well as more neurotic illness, than normal women. ${ }^{10-12}$ Those pregnancies which are followed by a puerperal psychosis tend to be shorter in duration and stormier than average, and are more likely to be associated with dystocia and to result in smaller babies having an increased perinatal mortality. ${ }^{4}$ These psychotic mothers are more often older than usual and primiparous, or they have had long intervals between their pregnancies. ${ }^{4}$ " Whether or not psychiatric symptoms arise during pregnancy depends largely on the patient's previous personality, bui several studies have shown an increase in neurotic symptoms in the puerperium, ${ }^{14} 15$ and "maternity blues" is a well-recognized phenomenon. E. D. M. $\operatorname{Tod}^{16}$ in a study of 700 consecutive pregnancies found $2.9 \%$ to be associated with postpartum depression heralded in each case by pathological anxiety during pregnancy. Indeed, in predicting the effect of any stress, whether it is normal labour, abortion, or an event unrelated to pregnancy, personality factors, habitual modes of adaptation, and the social situation must be taken into account. Careful evaluation of the patient certainly facilitates management and helps to prevent further disturbance. ${ }^{17}$

Prediction of the development of a puerperal psychosis is not based on secure ground. When a woman has had a previous puerperal psychosis the risk of recurrence with a subsequent pregnancy has been variously estimated as from one in seven ${ }^{18}$ to one in three, ${ }^{4}$ whereas the risk for a woman with a previous non-puerperal affective illness has been estimated at one in ten. ${ }^{19}$ Clearly, individual cases vary considerably. Some instances of more than nine consecutive puerperal disturbances have been reported, ${ }^{20}$ though normally recurrence is neither a regular nor an expected event. The one relatively certain expectation is that a subsequen: puerperal illness will take a similar form to the initial attack. '

Thus in the individual case there is little forewarning. The illness is almost invariably preceded by a lucid interval of from three to four days after delivery. ${ }^{21}$ Then the onset is acute, often with clouding of consciousness and an air of bewilderment and perplexity. ${ }^{22}$ These features may overshadow delusions or hallucinatory experiences of depressive kind, and possibly the differences in the reported prevalence and prognosis of puerperal schizophrenia are due to mislabelling of affective states. A recent study ${ }^{23}{ }^{24}$ reported five cases of affective illness for every two of schizophrenia, a similar proportion to that found among non-pregnant married women admitted to hospital for mental illness in the sam. age groups.

Thomas, C. L and Gordon, J. E. Amer. 7. med. Sci, 1959, 238 363.

Rosenberg, A. J., and Silver, E., Calif. Med., 1965, 102, 407

Pugh, T. F., et al., New Engl. f. Med., 1963, 268, 1224.

Paffenbarger, R. S., Brit. F. prev. soc. Med., 1964, 18, 189.

Hemphill, R. E., Brit. med. F., 1952, 2, 1232.

Jansson, B., Acta psychiat. scand., 1965, 41, 87.

Ekblad, M., Acta psychiat. (Kbh.), 1955, Suppl. No. 99.

Höök, K., Acta psychiat. scand., 1963, Suppl. No. 168.

Yarden, P. E., Max, D. M., and Eisenbach, Z., Brit. F. Psychiat., 1966 112,491 .

Mandelbrote, B. M., and Monro, M., Acta psychiat. scand., 1964, 40 419.

Engström, L., et al., 7. psychosom. Res., 1964, 8, 151.

Destounis, N., Dis. nerv. Syst., 1965, 26, 378.

Vislie, H., Acta psychiat. (Kbh.), 1956, Suppl. No. 111

Jacobson, L., Kaii, L., and Nilsson, A., Brit. med. F., 1965, 1, 1640

Kear-Colweli, J. J., Brit. F. Psychiat., 1965, 111, 1189.

Tod, E. D. M., Lancet, 1964, 2, 1264.

Cohen, R. L., Obstet. and Gynec., 1966, 27, 562.

Linn, L., and Polatin, P., Psychiat. Quart., 1950, 24, 375.

Winokur, G., and Ruangtrakool, S., f. Amer. med. Ass., 1966, 197 242 .

Jones, R., 7. Obstet. Gynaec. Brit. Emp., 1903, 3, 109.

Jones, R., f. Obstet. Gynaec. Brit. Emp., 1903, 3,
Paffenbarger, R. S., f. chron. Dis., 1961, 13, 161.

Hamilton, J. A., Postpartum Psychiatric Problems, 1962. London

Protheroe, C., M.D. Thesis, University of Sheffield, 1965.

Brit. \%. Psychiat., 1966, in press. 
Puerperal schizophrenia or affective disorder is thus mainly distinguished from the corresponding non-puerperal states by the acute onset, evident external and internal stress, the social situation, the marital status of the patients, and by their age-the schizophrenic patients being rather older and the patients with affective states younger at age of onset than is usual in non-puerperal patients. These factors are by and large associated with favourable outcome, and, since hese women are usually under medical surveillance, early dentification and treatment also improve the outlook. Early recognition and prompt treatment with phenothiazines, and the addition of an antidepressant drug where indicated, may make management in the maternity hospital feasible, with ninimal disruption of the family and to the developing mother-child relationship. When transfer to a psychiatric unit is required rapid control of the symptoms with electric convulsion therapy makes it easier to admit mother and child together, with correspondingly improved prospects of the nother successfully managing her child on discharge.

Puerperal psychosis presents a challenge to the investigator, for it gives an opportunity to examine a number of fundamental questions on the causation of mental disease. To the clinician the crucial issue is that early identification, with prompt treatment and minimal time in hospital, offers in these cases a good prospect of early recovery.

\section{The Ureter in Renal Transplantation}

In the last few years the results of kidney transplantation in man have much improved. This is owing to increasing experience with drugs such as azathioprine and prednisone which suppress the patient's immune response, and increasing use of renal dialysis on patients in terminal renal failure so that they are fit for the transplant operation. Tissue typing (like blood grouping) to select compatible donors will probably also increase the chances of long-term survival from renal grafting. These points are brought out in the article by Professor R. Y. Calne and his colleagues at page 1345 of the B.M.F. this week.

The surgical technique of renal transplantation is fairly well established. The renal vessels are anastomosed to the iliac vessels in the extraperitoneal plane, and the ureter is joined to the bladder. However, the exact mechanism of ureteric drainage has been a subject of debate. In view of the danger of ureteric reflux of urine after direct implantation of the ureter into the bladder, some surgeons have preferred to anastomose the transplanted ureter end-to-end to the patient's \lrcorner wn ureter after removing the patient's kidney. Others believe that a better anastomosis can be achieved by joining the patient's ureter direct to the pelvis of the transplanted tidney. F. Paccione and colleagues ${ }^{1}$ have shown that when a normal ureter is divided it immediately starts to swell owing to oedema of the adventitia. After a few days the oedema settles, but there is some permanent muscle atrophy and mild bydroureter even one to three years later. In the homotransplanted ureter the oedema is more severe and more muscle is lost. In addition there is cellular infiltration throughout the wall of the ureter, with a concentration of cells in the lamina propria. These authors considered that some of the mono-

Paccione, F., Enein, A. A., Shikata, T., and Dempster, W. J., Brit. F. exp. Path., 1965, 46, 519. nuclear cells, including plasma cells and lymphocytes, were migrating through the mucosal cells into the lumen of the ureter. Numerous mast cells were observed in all layers of the ureter, and Paccione and colleagues believe they could be a manifestation of a graft-host reaction. Certainly the rejection process in the ureter of homotransplanted kidneys follows the general pattern of rejection seen in the kidney.

The ureteric anastomosis can fail for a variety of reasons Firstly, there may be a direct technical fault in the performance of the anastomosis, resulting in leakage or stenosis Secondly, infection may occur in the wound, resulting in a urinary fistula. Thirdly, obstruction or mecrosis of the ureter may occur owing to immunological rejection.

A urinary fistula is an exceedingly grave complication in a patient with a renal transplant, since the immunosuppressive drugs impair the defences against infection and a septic fistulous tract is likely to follow. With ureto-ureteric or uretopelvic anastomoses the patient's own ureto-vesicle mechanism is preserved, but the anastomosis is relatively unprotected by surrounding structures. Some surgeons, therefore, believe it is preferable to implant the ureter into the bladder with an oblique tunnel to produce a valve and prevent urinary reflux. With this technique minor degrees of sepsis, rejection, or error in the placement of a suture will not necessarily result in urinary fistula, since $3-4 \mathrm{~cm}$. of the ureter lies within the bladder wall. A further advantage of this technique is that, if complications damage the ureter, it is still possible to anastomose the transplanted renal pelvis or ureter to one of the patient's own ureters.

\section{Rebound Thrombosis after Stopping Anticoagulants}

There is a clinical impression that fresh thrombotic attacks are apt to occur soon after anticoagulant treatment is stopped. The arguments have centred on whether this rebound thrombosis represents a temporary state of excessive coagulability or, as I. S. Wright has suggested, ${ }^{1}$ a "catching up " of progressive obliterative arterial disease after anticoagulant protection is withdrawn.

S. Sevitt and D. Innes, ${ }^{2}$ reviewing necropsy data, could find no evidence of rebound thrombosis after anticoagulant prophylaxis in accident surgery. But their patients received only short courses of anticoagulant treatment and did not have established thrombotic lesions. D. E. Sharland ${ }^{3}$ threw further doubts on the occurrence of rebound thrombosis after short-term therapy. In his study six deaths occurred among 137 patients whose treatment was stopped abruptly and two among 83 patients whose treatment was gradually withdrawn over periods between four and 42 days. The difference was not significant.

The situation may be different in patients who have received anticoagulants for longer periods. None of Sharland's patients had been on long-term treatment. J. Marshall, ${ }^{4}$ whose patients had all been on long-term therapy for four years, found that the recurrence rate in 61 patients with cerebrovascular strokes rose more than threefold in the

\footnotetext{
Wright, I. S., f. Amer. med. Ass., 1960, 174, 1921.

Sevitt, S., and Innes, D., Lancet, 1963, 2, 974

Sharland, D. E., Brit. med. F., 1966, 2, 392.

Marshall, J., Circulation, 1963, 28, 329.

Poller, L., and Thomson, J., Lancet, 1964, 2, 62.

_ Brit. med. F., 1965, 1, 1475.

Murphy, E. A., and Mustard, J. F., Lancet, 1961, 2, 960
} 